\title{
Glaucoma Screening in Family Members of Glaucoma Patients at a Tertiary Eye Hospital in Eastern Region of Nepal
}

\author{
Ravi Dhar Bhandari ${ }^{\otimes}$, Bandana Khanal ${ }^{2}$, Manish Poudel $^{2}{ }^{\mathbb{D}}$, Mohan Krishna Shrestha ${ }^{2}$, Suman Shamsher Thapa ${ }^{2}$ \\ 'Dhangadhi Netralaya, Dhangadhi, Nepal \\ Tilganga Institute of Ophthalmology, Kathmandu, Nepal
}

\begin{abstract}
Introduction: The second most common cause of blindness in the world is glaucoma. Family history plays an important role in early detection and management of patients with glaucoma. The main objective of this study was to determine the prevalence of glaucoma in first degree relatives of Primary open angle glaucoma (POAG) and Primary angle closure glaucoma (PACG) patients. Glaucoma awareness among the first degree relatives was also assessed.
\end{abstract}

Materials and methods: A cross sectional hospital based study was designed to examine and diagnose glaucoma among first degree relatives of patients with POAG and PACG, attending the outpatient department at Ramlal Golchha Eye Hospital in the Eastern region of Nepal from June 2016 to May 2017. A comprehensive eye examination was conducted by a glaucoma specialist at the hospital. All subjects underwent vision screening, refraction, slit lamp biomicroscopy, intraocular pressure (IOP) measurement, gonioscopy and a dilated fundus examination. All glaucoma suspects and those diagnosed with glaucoma were enrolled for visual field examination.

Results: Two hundred and twenty-seven first degree relatives of 72 patients were invited for the examination. Out of 227 individuals, 131 (males 67.94\%, females 32.06\%) agreed to participate in the study. A total of 23 (17.56\%) individuals were diagnosed with glaucoma, 10 (43.47\%) as POAG and $13(56.52 \%)$ as PACG. Fourteen percent of parents, 22\% of siblings and $9 \%$ of off-springs had open angle glaucoma. Among 13 PACG participants, $26.08 \%$ of parents, $26.08 \%$ of siblings and $4.34 \%$ of offsprings had angle closure glaucoma. Awareness among first degree relatives diagnosed with glaucoma was $21.74 \%$.

Conclusion: The prevalence of glaucoma among first degree relatives of glaucoma patients was higher than individuals without family history of glaucoma. Promoting awareness on glaucoma and the timely screening of family members can lead to early detection and prevention of blindness from the disease.

Key words: Family history, First degree relatives, Primary angle closure glaucoma, Primary open angle glaucoma.

Financial Interest : Nil Received : 08.10.2020

Conflict of Interest : Nil

Accepted : 01.01.2021

Corresponding Author

Dr. Ravi Dhar Bhandari

Dhangadhi Netralaya,

Dhangadhi, Nepal.

E-mail: drravi_np@hotmail.com

Contact: +9779848412968
Access this article online

Website: www.nepjol.info/index.php/NEPJOPH

DOI: https://doi.org/10.3126/nepjoph.v13i2.34673

Copyright $\odot 2021$ Nepal Ophthalmic Society

ISSN: 2072-6805, E-ISSN: 2091-0320

This work is licensed under a Creative Commons

Attribution-NonCommercial-NoDerivatives 4.0 International License (CC BY-NC-ND). 


\section{INTRODUCTION}

The second most common cause of blindness in the world is due to Glaucoma. It is a major cause of irreversible blindness (Resnikoff $\mathrm{S}$ et al., 2004; Kingman S, 2004; Quigley HA et al., 2006). The World Health Organization estimated that the prevalence of blindness from glaucoma amongst people over the age of fifty years is $3.4 \%$ in South East Asia (Pascolini D et al., 2004). It had been estimated that by 2010 , 60.5 million people globally would be affected by primary open-angle glaucoma (POAG) and primary angle-closure glaucoma (PACG) and $47 \%$ of those with glaucoma will be Asian (Kingman S, 2004; Quigley HA et al., 2006; Wong TY et al., 2006). By the year 2020, there will be 21 million people worldwide affected by PACG with a mean prevalence of $0.69 \%$ and $87 \%$ of them will reside in Asia. $70 \%$ of individuals with PACG will be women (Wong TY et al, 2006).

According to the Nepal Blindness Survey of 1981 in Nepal, glaucoma was the third most common cause of blindness after cataract and corneal diseases. Around $3.2 \%$ of the total blindness in Nepal was due to glaucoma (Brilliant LB et al., 1985). According to the Rapid Assessment of Avoidable Blindness (RAAB) surveys of 2012 and 2019, the average prevalence of blindness in Nepal was $2.5 \%$ and $1 \%$ in people aged 50 years and above respectively. Glaucoma was the third major cause of blindness in both surveys (Sapkota YD \& Hans L, 2013; Nepal Eye Program, 2019).

Family history of glaucoma (FHG) in first degree relatives is considered a major risk factor for the development of glaucomatous disease, which confirms a genetic cause for the causation of the disease (Gramer G et al., 2014). Patients of first degree relatives with glaucoma have a 10 times greater risk of developing glaucoma than those with no family history (Wolfs RC et al., 1998). Majority of glaucoma patients are asymptomatic and at the time of diagnosis and have suffered an irreversible visual field loss (Hitchings RA, 1993).

It has been suggested that 1 in 8 persons with open angle glaucoma has a living relative with undetected glaucoma (Quigley HA, 2006). First degree relatives of glaucoma patients have an increased risk of glaucoma as compared to individuals without a family history of glaucoma (POAG). Screening of first degree relatives for glaucoma showed that the percentage of glaucoma was higher among family members (Kong X et al., 2013). About 90\% of open angle glaucoma are presently undiagnosed in developing communities and screening first degree relatives may be a cost-effective method to find at least a proportion (Rajendrababu $\mathrm{S}$ et al., 2014). Family history is a major risk factor for the prevalence of angle closure glaucoma. Siblings of angle-closure patients had a more than 1 in 3 risk of prevalent angle closure, whereas siblings of PAC/PACG patients had a more than $10 \%$ risk of prevalent $\mathrm{PAC} / \mathrm{PACG}$ (Kavitha $\mathrm{S}$ et al., 2014). Siblings of Chinese patients with PAC or PACG have almost a $50 \%$ probability of having narrower angles than the general population (Amerasinghe $\mathrm{N}$ et al., 2011). A study in a rural population in south India showed the prevalence of PAC/ 
PACG to be $1.58 \%$ (Vijaya L et al., 2006). In the Bhaktapur Glaucoma Study, the prevalence of glaucoma was $1.9 \%$. Although POAG was the most common form of glaucoma, the visual morbidity from PACG was higher (Thapa SS et al., 2012).

Relatives of glaucoma patients are often unaware of the risk of glaucoma, sometimes even decades after treatment is initiated in their family (McNaught AI et al., 2000). The awareness of glaucoma was $2.4 \%$ in the general population and is significantly lower in females as compared to males (Thapa SS et al., 2011).

Primary Open Angle Glaucoma is more genetically influenced whereas PACG is morphologically influenced, however there are genes linked to PACG. Genes associated with forms of glaucoma exhibit autosomaldominant, autosomal-recessive, and other inheritance patterns. Positive family history is a risk factor for POAG, and previous studies have shown that approximately $5 \%$ of it is due to mutations in the myocilin (MYOC) gene. POAG associated loci involve diverse biological processes (McNaught AI et al., 2000; Frezzotti R et al., 2004; Wiggs JL et al., 1998).

Genome wide association studies have identified 8 genes/loci for the common adult-onset form of PACG (Vithana EN et al., 2012; Khor CC et al., 2016).

The purpose of our study was to find out the prevalence of glaucoma among family members of glaucoma patients. To the best of our knowledge this is the first study where family members of glaucoma patients have been screened for the disease.

\section{MATERIALS AND METHODS}

This is a cross sectional hospital based study, which was done in Ramlal Golchha Eye Hospital from June 2016 to May 2017. The study was approved by the Institutional Review Committee of Tilganga Institute of Ophthalmology. First degree relatives of patients with glaucoma were included in the study. There were 227 first degree relatives of 72 individuals who were previously diagnosed with POAG/ PACG. Out of which, 143 first degree relatives attended the hospital for glaucoma screening, and among them 12 refused to undergo investigation. [Response rate $62.99 \%$ ].

All of subjects underwent a comprehensive eye examination, which included vision screening (logarithm of minimal angle of resolution), refraction, slit lamp biomicroscopy (Haag Streit BM 900 model), intraocular pressure (IOP) measurement (Goldmann applanation tonometer), gonioscopy (Zeiss 4 mirror gonio lens) where the angle was graded according to the Shafer system (Shaffer RN et al, 1960), if the angle was occludable, indentation gonioscopy was performed and the presence or absence of peripheral anterior synechiae was recorded, an angle closure of 270 degrees or more was considered as closed angles and dilated fundus examination was done with 90D lens and the vertical cup/ disk ratio, neural rim thinning, notching of optic nerve head, nerve fiber hemorrhages, and retinal nerve fiber layer abnormalities were noted. Optic disk 
photographs were not taken. Visual field testing was carried out on Humphrey Field Analyser, All the individuals diagnosed as glaucoma suspects, POAG and PACG were advised to perform a visual field test using the SITA standard 24-2. When the visual field showed glaucomatous defects, a second field was repeated to confirm the presence of the defects. Glaucomatous disc changes included vertical C:D ratio $>0.6$, focal notch, NRR $<0.1$ in superior or inferior quadrant, disc haemorrhage, nerve fiber layer loss, and cup asymmetry between the two eyes of $>0.2$ when disc size was the same for both eyes.

Those patients with an IOP of less than 21 $\mathrm{mmHg}$, without optic disc neuropathy were considered to be normal. Those patients with an IOP of greater than or equal to $21 \mathrm{mmHg}$ in either eye or with suspicious optic disc changes for glaucoma were termed glaucoma suspects. POAG was defined as those with open angles on gonioscopy, glaucomatous optic disc changes and visual field defects. PACG was defined as those with closed angles on gonioscopy more than 270 degrees, glaucomatous optic disc changes and visual field defects.

All collected data were entered into Microsoft excel 2007 and data was analysed using SPSS version 19.0 (IBM SPSS Statistic for Windows, Armonk, NY, IBM Corp. Released 2010)

For association of categorical data, the Chi square / Fisher exact test was used wherever applicable. For numeral normally distributed data Independent t-test was used. P value $<0.05$ was considered statistically significant.

\section{RESULTS}

Out of 237 first degree relatives, 143 (56.54\%) attended the hospital for screening of glaucoma, $12 \quad(8.39 \%)$ participants refused to be included in the study. Out of 131 individuals $89(67.94 \%) \quad$ participants weremalesand $42(32.06 \%)$ werefemales (Table 1). A total of $23(17.56 \%)$ persons were diagnosed as glaucoma. Age and sex distribution of the participants are shown in Table 2 .

Table 1: Total percentage of individual for glaucoma screening.

\begin{tabular}{|c|c|c|}
\hline Male, $\mathbf{n}(\mathbf{\%})$ & Female, $\mathbf{n}(\mathbf{\%})$ & Total, $\mathbf{n}(\%)$ \\
\hline $89(67.94)$ & $42(32.06)$ & $131(100)$ \\
\hline
\end{tabular}

Table 2: Age and sex of the individuals diagnosed as glaucoma.

\begin{tabular}{|c|c|c|c|}
\hline Age (Years) & Male, $\mathbf{n}(\%)$ & Female, $\mathbf{n}(\%)$ & Total, $\mathbf{n}(\%)$ \\
\hline Mean (SD) & $63.73(21.00)$ & $51.2(21.40)$ & $57.17(21.67), \mathrm{p}=0.17$ \\
\hline$<20$ & $1(9.09)$ & $2(16.67)$ & $3(13.05)$ \\
\hline $20-40$ & $1(9.09)$ & $3(25)$ & $4(17.39)$ \\
\hline $40-60$ & $4(36.36)$ & $3(25)$ & $7(30.43)$ \\
\hline $60>$ & $5(45.45)$ & $4(33.33)$ & $9(39.13)$ \\
\hline Total & $11(47.83)$ & $12(52.17)$ & $23(100)$ \\
\hline
\end{tabular}


Table 3: Gender distribution of the disease.

\begin{tabular}{|c|c|c|c|}
\hline Gender & PACG, $\mathbf{n}(\mathbf{\%})$ & POAG, $\mathbf{n}(\mathbf{\%})$ & p value \\
\hline Male & $6(46.15)$ & $5(50)$ & \\
\cline { 1 - 3 } Female & $7(53.85)$ & $5(50)$ & 1.00 \\
\hline Total & $13(56.52)$ & $10(43.48)$ & \\
\hline
\end{tabular}

The mean (SD) age of the patients diagnosed as glaucoma was $57.18 \pm 21.66$ years. Out of 23 individuals diagnosed as glaucoma, 12 $(52.17 \%)$ were females and $11(47.83 \%)$ males. Thirteen $(56.5 \%)$ were diagnosed as PACG and $10(43.47 \%)$ as POAG. Among 10 POAG participants, $14 \%$ of parents, $22 \%$ siblings and 9\% off-springs had open angle glaucoma. Among 13 PACG participants, 26\% of parents, $26.08 \%$ siblings, $4.34 \%$ off-springs had angle closure glaucoma. Out of 10 POAG participants, $5(50 \%)$ were females and $5(50 \%)$ males (Table 3). Out of 13 PACG participants, 7 (53.85\%) were females and $6(46.15 \%)$ males.
There were two families that presented with PACG in 3 generations (parents, siblings, and offspring). Similarly, there were two families that presented with POAG in two generations. In one of the families, parents and siblings had POAG whereas in the other sibling and offspring had POAG. Two of the screened individuals were under anti glaucoma medications. Out of 23 individuals diagnosed with glaucoma, only $5(21.7 \%)$ were aware, of which $4(36.36 \%)$ were males and $1(8.33 \%)$ was female $\mathrm{p}=0.155$. Similarly, out of 131 individuals, only $24(18.32 \%)$ were aware, of which 12 (13.48\%) were males and 12 (28.57\%) were females $\mathrm{p}=0.037$ (Figure 1).

\section{Family history of glaucoma awareness}

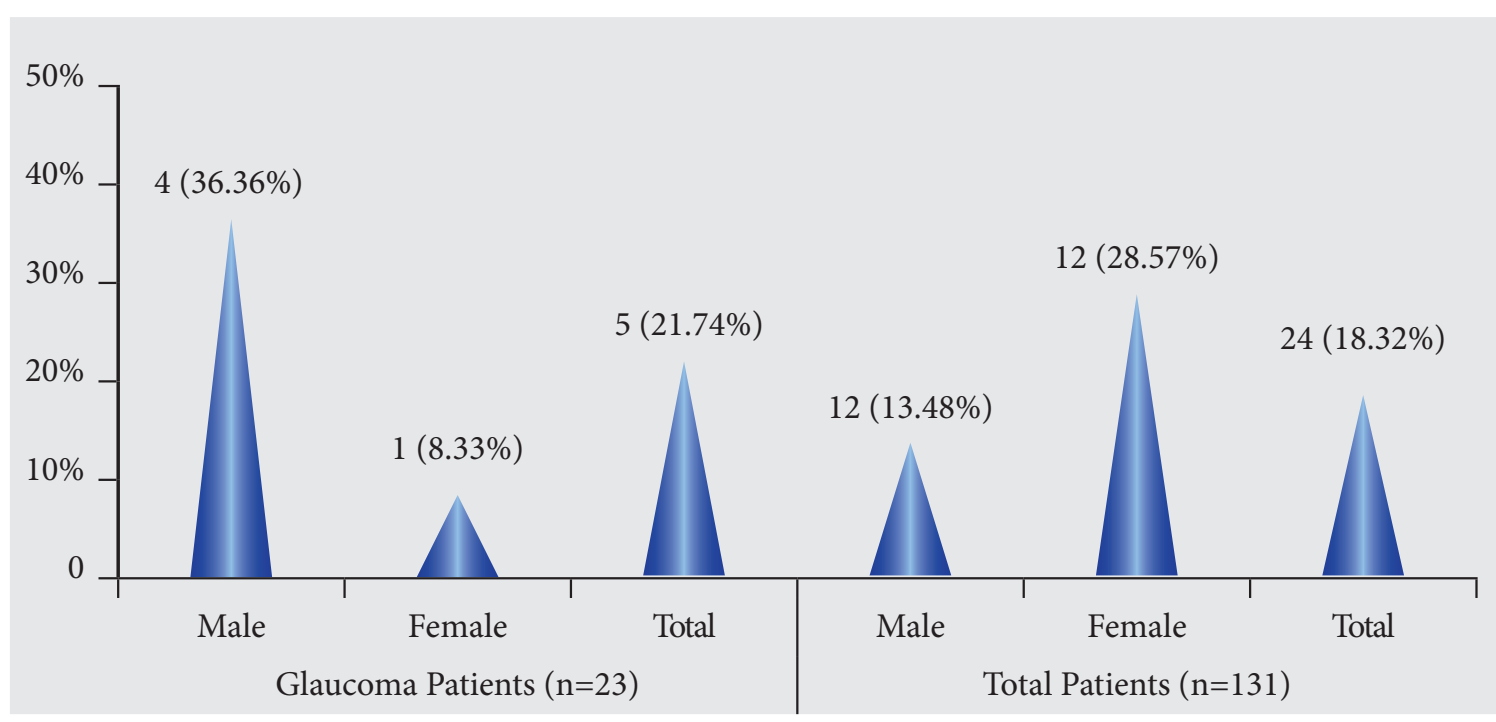

Figure 1: Awareness of glaucoma in family. 


\section{DISCUSSION}

The prevalence of glaucoma among the first degree relatives screened in our study was $17.56 \%$, of which $56.5 \%$ were PACG and $43.47 \%$ were POAG. To the best of our knowledge, there are no studies on screening of family members for glaucoma conducted in Nepal, therefore we are unable to compare our findings to other studies in our country. However there are studies comparing the first degree relatives in our neighboring countries, Indian subcontinent and China, where family members were screened for glaucoma (Rajendrababu S et al, 2014; Gupta P et al 2018; Kong X et al, 2013; Kong $X$ et al, 2011). The risk of developing POAG in first-degree relatives in India ranged from 4-16\% (Rajendrababu $\mathrm{S}$ et al, 2014; Gupta P et al, 2018). Five hundred and fourteen first-degree relatives of POAG patients were included in the study. Among them, 68 (13.3\%) had glaucoma while another 28 (5.5\%) had ocular hypertension or were glaucoma suspects (Rajendrababu S et al, 2014). Similarly, (Gupta P et al, 2018) found that the prevalence of glaucoma in first degree relatives of patients with POAG was $16.7 \%$. Whereas studies from China showed the risk of glaucoma among family members ranging from $4.82 \%-12.62 \%$ (Kong X et al, 2013; Kong X et al, 2011). In other regions of the world the prevalence of glaucoma among family members ranged from 5-16.79\% (Gramer G et al, 2014; Gramer E et al, 2003; Vegini $F$ et al, 2008). In comparison to the above studies our findings were almost similar.
There was no alteration of the disease as patients with POAG/PACG did not have a family member of PACG/POAG in our study population. A total of 442 individuals from five pedigrees with a positive family history of POAG were examined in the Glaucoma Inheritance Study. Among them, 13\% had a prior diagnosis of POAG or were glaucomasuspects, and 16\% were newly diagnosed. A high prevalence rate was reported in first-degree relatives $(38.6 \%)$ which could have been due to the pedigrees with a positive history of glaucoma that were included in the study (McNaught AI et al, 2000). Another study conducted by (Wu $\mathrm{J}$ et al, 2006), compared the familial group with the sporadic POAG group. Among 1200 individuals with a positive family history of POAG, 64.8\% had glaucoma in first-degree, $10.9 \%$ in second-degree, $10.2 \%$ in third-degree relatives. The above two studies have proven that glaucoma has a higher prevalence among family members.

In our study almost one in eight individuals of first degree relatives were diagnosed with glaucoma. We had more PACG patients than POAG in our study. The reason for this could be the small sample size and that PACG patients attended hospital more frequently due to the symptomatic nature of the disease.

The age of individuals with glaucoma ranged from 16 to 82 years. The mean age was $57.18 \pm$ 21.66 years. There were $3(13.04 \%)$ patients with glaucoma who were less than 20 years of age, and among them 2 (8.69\%) had glaucoma 
in two generations. A higher prevalence of glaucoma amongst siblings and offspring ranging from $1-4 \%$ and $10-15 \%$ among siblings has been reported (Wolfs RC et al, 1998). There was more than $10 \%$ risk of developing PAC or PACG among siblings of angle-closure patients (Kavitha S et al, 2014).

Our study showed that a large majority of individuals were unaware of glaucoma in their family despite glaucoma being a familial disease. A low awareness $2.4 \%$ on glaucoma has also been reported by the Bhaktapur Glaucoma Study (Thapa SS et al, 2011). Similarly (Gupta $\mathrm{P}$ et al, 2018) found $66.7 \%$ of the patients were aware of family history of glaucoma, of them only $36.4 \%$ were aware of the risk of glaucoma. Yazd eye study showed $89.7 \%$ were unaware of glaucoma at presentation (Pakravan M et al, 2013). In the future, awareness of glaucoma has to be promoted in the general population especially among those with a family history of glaucoma.

This is the first study in Nepal where family members were screened for glaucoma. The limitation of our study was inability to screen all family members as some of the members were outside the country.

\section{CONCLUSION}

The prevalence of glaucoma was higher among first degree relatives of glaucoma patients. Promoting awareness on glaucoma and the timely screening of family members can lead to early detection and prevention of blindness from the disease. The importance of glaucoma screening has to be emphasized to patients with glaucoma to bring forth their family members.

\section{REFERENCES}

Amerasinghe N, Thalamuthu A, He M, Vithana EN, Viswanathan A, Wong TY, et al (2011). Heritability and Sibling Risk of Narrow Angles. Ophthalmology;118(3):480-5. doi: 10.1016/j.ophtha.2010.06.043; PMid:21035870

Brilliant LB, Pokhrel RP, Grasset NC, Lepkowski JM, Kolstad A, Pararajasegaram R, et al (1985). Epidemiology of blindness in Nepal. Bull World Health Organ;63(2):375-86.

Frezzotti R, Renieri A, Frezzotti P (2004). Adult-onset primary glaucoma and molecular genetics: A review. European Journal of Ophthalmology;14:220-5. doi: 10.1177/112067210401400306; PMid:15206647

Gramer E, Gramer G(2003). Significance of Family History of Glaucoma for Glaucoma Screening. Invest. Ophthalmol Vis Sci;44(13):2189.

Gramer G, Weber BH, Gramer E (2014). Results of a patient-directed survey on frequency of family history of glaucoma in 2170 patients. Invest Ophthalmol Vis Sci;55(1):259-64. doi: 10.1167/iovs.13-13020; PMid:24327611

Gupta P, Vijaya P (2018). Prevalence of glaucoma in first degree relatives of patients with primary open-angle glaucoma and normal-tension glaucoma. Asian Journal of Ophthalmology;16:95-100. doi: 10.35119/asjoo.v16i2.374 


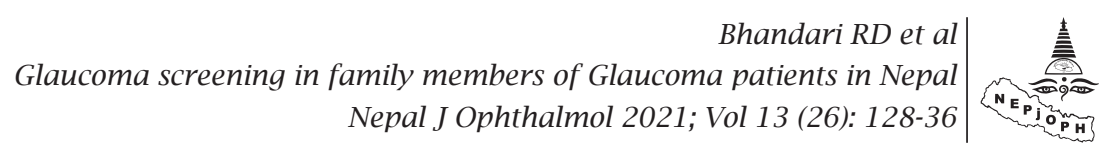

Hitchings RA (1993). Glaucoma screening. Br J Ophthalmol;77(6):326. doi: 10.1136/bjo.77.6.326; PMid:8318476

Kavitha S; Zebardast N; Palaniswamy K; Wojciechowski R; Chan ES; Friedman DS; Venkatesh R; Ramulu PY. Family History Is a Strong Risk Factor for Prevalent Angle Closure in a South Indian Population. Ophthalmology 2014; 121: 2091-2097 (IGR: 16-2)

Ramulu PY (2014). Family history is a strong risk factor for prevalent angle closure in a South Indian population. Ophthalmology;121(11):2091-7. doi: 10.1016/j.ophtha.2014.05.001; PMid:24974379

Khor CC, Do T, Jia H, Nakano M, George R, Abu-Amero K, et al (2016). Genome-wide association study identifies five new susceptibility loci for primary angle closure glaucoma. Nat Genet;48:556-62. doi: 10.1038/ng.3540; PMid:27064256

Kingman S (2004). Glaucoma is the second leading cause of blindness globally. Bull World Health Organ;82:887-8.

Kong X, Chen Y, Chen X, Sun X (2011). Influence of family history as a risk factor on primary angle closure and primary open angle glaucoma in a Chinese population. Ophthalmic Epidemiol; 18(5):226-32. doi: 10.3109/09286586.2011.595040; PMid:21961512

Kong X, Zhu W, Chen X, Chen Y, Sun X (2013). Familial aggregation of primary open angle glaucoma in Shanghai. China. Mol Vis;19:1859-65.

McNaught AI, Allen JG, Healey DL, McCartney PJ, Coote MA, Wong TL, et al (2000). Accuracy and implications of a reported family history of glaucoma: Experience from the Glaucoma Inheritance Study in Tasmania. Arch Ophthalmol;118(7):900-4.

Nepal Eye Program (2019). Summary report rapid assessment of avoidable blindness in province 3. Kathmandu, Nepal.

Pakravan M, Yazdani S, Javadi MA (2013). A population-based survey of the prevalence and types of glaucoma in central Iran: the Yazd eye study. Ophthalmology;120(10):1977-84. doi: 10.1016/j.ophtha.2013.02.029; PMid:23664464

Pascolini D, Mariotti SP, Pokharel GP, Pararajasegaram R, Etya'ale D, Négrel AD， et al. (2004). 2002 Global Update of Available Data on visual Impairment: a compilation of population-based prevalence studies. Ophthalmic Epidemiol;11: 67-115. doi: 10.1076/opep.11.2.67.28158; PMid:15255026

Quigley HA (2006). Chase the family. Arch Ophthalmol;124(7):1036-7. doi: 10.1001/archopht.124.7.1036; PMid:16832029

Quigley HA, Broman AT (2006). The number of people with glaucoma worldwide in 2010 and 2020. Br J Ophthalmol;90:262-7. doi: 10.1136/bjo.2005.081224; PMid:16488940

Rajendrababu S, Gupta N, Vijayakumar B, Kumaragurupari R, Krishnadas SR (2014). Screening First Degree Relatives of Persons with Primary Open Angle Glaucoma in India. Journal of current glaucoma practice; 8(3):107112. doi: 10.5005/jp-journals-10008-1172; PMid:26997821

Resnikoff S, Pascolini D, Etya'ale D, Kocur I, Pararajasegaram R, Pokharel GP, et al. (2004). Global data on visual impairment in the year 2002. Bull World Health Organ; 82(11):844-51. doi: 10.1076/opep.11.2.67.28158; PMid: 15255026

Sapkota YD \& Hans L. (2013). Epidemiology of Blindness in Nepal: 2012.

Shaffer RN (1960). Symposium: primary glaucomas. Gonioscopy, ophthalmoscopy and perimetry. Trans Am AcadOphthalmol Otol; 62:112. 
Thapa SS, Berg RV, Khanal S, Paudyal I, Pandey P, Maharjan N, Twyana SN, Paudyal G, Gurung R, Ruit S (2011): Prevalence of visual impairment, cataract surgery and awareness of cataract and glaucoma in Bhaktapur district of Nepal: the Bhaktapur Glaucoma Study. BMC Ophthalmol; 11:2. doi: 10.1186/1471-2415-11-2; PMid:21255382

Thapa SS, Paudyal I, Khanal S, Twyana SN, Paudyal G, Gurung R, Ruit S, Van Rens GH (2012). A population based survey of the prevalence and types of glaucoma in Nepal: the Bhaktapur Glaucoma Study. Ophthalmology. Apr;119(4):759-64.

doi: 10.1016/j.ophtha.2011.10.021; PMid:22305097

Vegini F, Figueiroa Filho N, Lenci RF, Garcia Neto D (2008), Susanna Junior R. prevalence of open angleglaucoma in accompanying first degree relatives of patients with glaucoma. Clinics (Sao Paulo); 63(3):329-332. doi: 10.1590/ S1807-59322008000300007; PMid:18568241

Vithana E.N., Khor C.C., Qiao C., Nongpiur M.E., George R., Chen L.J., Do T., Abu-Amero K., Huang C.K., Low S.. et al. (2012). Genome-wide association analyses identify three new susceptibility loci for primary angle closure glaucoma. Nat. Genet., 44, 1142-1146. doi: 10.1038/ng.2390; PMid:22922875

Vijaya L, George R, Arvind H, et al. (2006). Prevalence of Angle-Closure Disease in a Rural Southern Indian Population. Arch Ophthalmol.; 124(3):403-409. doi: 10.1001/archopht.124.3.403; PMid:16534061

Wiggs J.L. (2015). Glaucoma genes and mechanisms. Prog. Mol. Biol. Transl. Sci.; 134, 315-342. doi: 10.1016/ bs.pmbts.2015.04.008; PMid:26310163

Wiggs JL, Allingham RR, Vollrath D. (1998). Prevalence of mutations in TIGR/Myocilin in patients with adult and juvenile primary open-angle glaucoma. Am J Hum Genet. 63:49-52. doi: 10.1086/302098; PMid:9792882

Wolfs RC, Klaver CC, Ramrattan RS, van Duijn CM, Hofman A, de Jong PT (1998). Genetic risk of primary openangle glaucoma. Population-based familial aggregation study. Arch Ophthalmol; 116(12):1640-1645. doi: 10.1001/ archopht.116.12.1640; PMid:9869795

Wong TY, Loon SC, Saw SM (2006). The epidemiology of age related eye diseases in Asia. Br J Ophthalmol;90:506-11. doi: 10.1136/bjo.2005.083733; PMid:16547337

Wu J, Hewitt AW, Green CM, Ring MA, McCartney PJ, Craig JE, Mackey DA (2006). Disease severity of familial glaucoma compared with sporadic glaucoma. Arch Ophthalmol; 124(7):950-954. doi: 10.1001/archopht.124.7.950; PMid:16832017 